<smiles>[C-]1C=C[CH-]C1</smiles>

\title{
La práctica docente como medida de valoración de los componentes del proceso de enseñanza y aprendizaje
}

Teaching practice as a measure of assessment of the components of the teaching and learning process

A prática de ensino como medida de avaliação dos componentes do processo de ensino e aprendizagem

\author{
Said Morales-Gamarra ${ }^{1}$ \\ Universidad Autónoma Juan Misael Saracho, Bolivia \\ https://orcid.org/0000-0002-6411-7553
}

Araceli Morales

Universidad Autónoma Juan Misael Saracho, Bolivia https://orcid.org/0000-0002-0026-3762

\author{
Angela Tejerina \\ Universidad Autónoma Juan Misael Saracho, Bolivia \\ https://orcid.org/0000-0001-5523-0880
}

D0I: https://doi.org/10.35622/j.rep.2021.03.002e

Recibido 02/12/2020/ Aceptado 20/07/2021

\begin{abstract}
RESUMEN. El presente trabajo de investigación enfatiza la importancia de la evaluación del desempeño docente en el proceso de formación que permite describir sus características desde una perspectiva del proceso enseñanza aprendizaje PEA, un factor preponderante hacia una educación de calidad, es por esta razón que se transversaliza la función formativa desde una perspectiva integral del docente estudiante, cuya la labor educativa dentro del aula es fundamental, debido a que debe articularse la oferta formativa con los propósitos de la malla curricular. En la actualidad las universidades enfrentan retos y desafíos para poder elevar la calidad de formación de los estudiantes, buscando la competitividad y adecuados al contexto en donde se desenvuelvan. Los resultados de este estudio serán de mucha utilidad para una mejora continua ya que permitirá una radiografía de la labor educativa buscado mejorar ésta en sus diferentes niveles. El concepto de educación como bien público repercute en la asociación de la calidad de educación superior e inclusión social. El Problema del presente estudio está centrado en poder describir el siguiente hilo conductor de la investigación cuáles son los factores que inciden en la práctica docente en el proceso del PEA en la Carrera de Administración de Empresas de la UAJMS en la ciudad de Tarija. Se trabajó con una población de 360 estudiantes y una muestra estratificada de 17 estudiantes a los cuales se les aplicó una encuesta para el estudio. El tipo de investigación utilizada fue la investigación exploratoria y descriptiva. Llegando al análisis y conclusión del presente estudio.
\end{abstract}

PALABRAS CLAVE: Evaluación del desempeño, juicios de valor, seguimiento.

ABSTRACT. This research work emphasizes the importance of the evaluation of teacher performance in the training process that allows describing its characteristics from a perspective of the teaching-learning process PEA, a preponderant factor

${ }^{1}$ Correspondencia: saidrodrigogamarra2@gmail.com 
towards quality education, it is for this reason that the formative function from an integral perspective of the student-teacher, whose educational work within the classroom is fundamental, because the training offered must be articulated with the purposes of the curriculum. Currently, universities face challenges and challenges to be able to raise the quality of student training, seeking competitiveness and appropriate to the context in which they operate. The results of this study will be very useful for continuous improvement since it will allow an $x$-ray of the educational work sought to improve it at different levels. The concept of education as a public good affect the association of the quality of higher education and social inclusion. The Problem of the present study is focused on being able to describe the following common thread of the investigation which are the factors that influence the teaching practice in the PEA process in the Business Administration Career of the UAJMS in the city of Tarija. We worked with a population of 360 students and a stratified sample of 17 students to whom a survey was applied for the study. The type of research used was exploratory and descriptive research. Coming to the analysis and conclusion of the present study.

KEYWORDS: Performance evaluation, value judgments, monitoring.

RESUMO. Este trabalho de investigação destaca a importância da avaliação do desempenho docente no processo formativo que permite descrever as suas características numa perspetiva do processo ensino-aprendizagem PEA, factor preponderante para uma educação de qualidade, razão pela qual a formação funciona a partir de uma perspectiva integral do aluno-professor, cujo trabalho pedagógico em sala de aula é fundamental, pois a oferta formativa deve estar articulada com as finalidades do currículo. Atualmente, as universidades enfrentam desafios e desafios para serem capazes de elevar a qualidade da formação para os alunos, buscando competitividade e adequação ao contexto em que atuam. Os resultados deste estudo serão de grande utilidade para a melhoria contínua, uma vez que permitirá uma radiografia do trabalho educacional que se buscou aprimorá-lo em diferentes níveis. 0 conceito de educação como um bem público afeta a associação entre a qualidade do ensino superior e a inclusão social. 0 problema do presente estudo está focado em ser capaz de descrever o seguinte fio comum da investigação quais são os fatores que influenciam a prática docente no processo de PEA na Carreira de Administração de Empresas da UAJMS na cidade de Tarija. Trabalhamos com uma população de 360 alunos e uma amostra estratificada de 17 alunos aos quais foi aplicada uma pesquisa para 0 estudo. 0 tipo de pesquisa utilizada foi a pesquisa exploratória e descritiva. Chegando à análise e conclusão do presente estudo.

PALABRAS CLAVE: Avaliação de desempenho, julgamentos de valor, monitoramento.

\section{INTRODUCCIÓN}

La evaluación del desempeño debe ser un proceso continuo y periódico, además debe ser íntegra de acuerdo a los resultados y a las competencias laborales de los trabajadores, conjuntamente con los objetivos estratégicos de la entidad. Este proceso actuará como vehículo para la puesta en práctica de la estrategia y la obtención con eficacia, eficiencia y calidad de las metas y objetivos de la entidad (Ayalas, 2004).

En la educación superior a diferencia de los sectores productivos, la incorporación de las tecnologías de informática y comunicaciones, no ocasiona reemplazo de factores (tecnología por docentes), ni desarrolla obligatoriamente la productividad de todos los factores, tampoco minimiza el tiempo de producción del bien (dígase ingenieros, médicos, físicos, o productos intelectuales) (González, Hidalgo y Lombillo, 2017). 
En la actualidad, la discusión sobre la evaluación docente no gira en torno a si debe evaluarse o no, más bien, el problema estriba en cómo hacerlo, quién lo hace, con qué propósito y cuál es la metodología apropiada (Chacón, 2001), por lo que se espera que la evaluación docente haga parte de una cultura de la evaluación y se convierta en una práctica cotidiana, capaz de generar cambios positivos en los procesos educativos. Sólo así podrá proporcionar información valiosa para que las instituciones fortalezcan su gestión con planes de mejoramiento ajustados a sus particularidades, para lograr mejoras en el sistema educativo.

Por ende, se debe considerar que en este arduo proceso de evaluación del desempeño docente todos ganan: las instituciones educativas, al mejorar su personal docente; el docente, al potenciar y mejorar aspectos con deficiencias; el estudiante, al recibir una mejor calidad de educación; la sociedad, pues existirán en un futuro profesionales de calidad que brindarán servicio a las necesidades de la misma.

Desde esta perspectiva hay que entender la propuesta que hace Luviano (2008) cuando señala que la evaluación de los docentes debe pensarse como un fundamento para la elaboración de planes y programas de mejoramiento y que requiere de diversas miradas, por lo que es necesario concurrir en varios instrumentos que aporten una información procedente de diferentes fuentes, momentos o procedimientos, ya que no hay instrumento que haya sido técnicamente elaborado y que pueda dar la información suficiente sobre la calidad del docente.

Según Elizalde y Reyes (2008) la evaluación del desempeño es el proceso en el cual se mide el grado en que cada trabajador mantiene su idoneidad y cumple los objetivos del cargo o puesto de trabajo que desempeña (eficacia), así como la forma en que utiliza sus recursos para lograr dichos objetivos (eficiencia).

Como consecuencia del desarrollo y madurez alcanzada por la educación superior, y la responsabilidad de las universidades en el Siglo XXI, es evidente que su gestión necesita un cambio y ese cambio pasa por la aplicación de técnicas novedosas, entre las que empieza a ocupar un lugar importante la gestión del capital humano (Favrod, 2002), por lo que debido 
a su creciente interacción con el entorno, existe una conciencia más clara de la necesidad de producir cambios que propicien una mayor participación, compromiso y motivación en el cumplimiento exitoso de la misión y los objetivos estratégicos (Fonseca, 2018).

Esos cambios están encaminados hacia la actualización de los equipamientos y las tecnologías, así como, en los métodos y estilos de liderazgo que coadyuven a una mayor participación, comprometimiento, motivación y creatividad de todo su capital humano como sujetos activos de las transformaciones requeridas e indicador decisivo de la excelencia universitaria.

Sobre esto plantean Lau y Díaz (2009) que los estudios e investigaciones deben encaminarse hacia los procesos de selección para el ingreso a la organización, la promoción de categorías docentes, la organización del trabajo, la evaluación del desempeño, los sistemas de estimulación, la formación y desarrollo, entre otros.

Para Llerena (1991) es una estrategia académica que permite identificar y atender en forma pertinente los problemas asociados al desempeño académico y profesional de los docentes, con la finalidad de verificar, retroalimentar y mejorar la calidad de los procesos de enseñanza-aprendizaje.

Marczely (1992) define a la evaluación del desempeño docente como un proceso cuya finalidad es emitir juicios de valor sobre el cumplimiento de sus responsabilidades en la enseñanza-aprendizaje y desarrollo de sus estudiantes. Tales criterios en la evaluación estarán referidos a la idoneidad ética y pedagógica que requiere la prestación del servicio educativo y toma en cuenta aquellos aspectos propios de las funciones docentes.

Según Escudero (2006) es un proceso sistemático de obtención de datos válidos y fiables, sobre las actividades que el profesor realiza como son: la docencia, investigación, tutorías, asesorías de tesis, superación, trayectoria académica, y vinculación con la extensión universitaria, cuyos resultados contribuyan al desarrollo profesional y desarrollo institucional.

La evaluación del desempeño docente es un proceso permanente, enmarcado dentro de 
una concepción de calidad de la educación, y enfocado hacia el perfeccionamiento de la docencia en una institución educativa Rizo (1999) entendida como vía para la mejora (Pérez, 1995; López, 1999), logrando que su labor deba ser cada vez más científica, moderna y de rigor, para que sea favorecedora de nuevas transformaciones lográndose mayores niveles de eficiencia y eficacia de los procesos docentes y en la satisfacción creciente de las demandas sociales.

Mediante la evaluación del desempeño decente es posible identificar la medida en que se logran los propósitos de los profesores, se conocen las causas del buen éxito o del fracaso y permite tomar decisiones para mejorar.

Existe la necesidad de poder contar con estos tipos de estudios ya que permitirán mejorar los procedimientos que en muchos casos no guardan relación con los objetivos propuestos, pues según evaluaciones realizadas por la universidad, éstas se realizaron después de varias gestiones no siendo oportunas y objetivas ya que el tiempo trascurrido, que en muchos casos pasaron varias gestiones para poder realizar dichas evaluaciones del desempeño docente, en muchos casos los estudiantes quienes son los que evalúan el desempeño docente se retiran de la universidad o culminan sus estudios y al momento de requerirlos no se encuentran siendo perjudicados los docentes evaluados ya que no se puede concluir con la evaluación de la misma.

El objetivo del presente trabajo de investigación es analizar las características de los componentes del PEA y cuyo aporte importante por parte de los estudiantes de tercer año de la Carrera de Administración de empresas.

\section{MATERIALES Y MÉTODOS}

Para conseguir este propósito se consideró la investigación exploratoria para la obtención de información, con el fin de elaborar los antecedentes revisión de datos aplicando las encuestas respectivas La investigación descriptiva porque dichos estudios buscan especificar las propiedades, las características de las personas que se someten a un análisis cuyos estudios son la base de los resultados. 
Se trabajó con una población de 350 personas y una asignación muestral mediante el muestreo aleatorio simple con un margen de error del 5\% y se determinó una muestra de 17 encuestas aplicadas a estudiantes de la carrera de administración de empresas. El estudio comprende una estructura, que abarca tantos aspectos generales y específicos de la labor formativa.

Posteriormente se presenta los resultados de las variables analizadas como son la planificación- organización y desarrollo de la materia, la metodología de evaluación del proceso de enseñanza aprendizaje, el uso de recursos didácticos y aspectos integrales como la puntualidad y dedicación por parte del sector docente, posterior se complementa otros estudios con otros niveles de formación dentro de la carrera de formación profesional. Se trabajó con un error de 6\% por el contratiempo que podría incurrir en el llenado de la encuesta. Para la distribución de porcentaje en el éxito y fracaso se lo determinó mediante una encuesta piloto a través de una muestra aleatoria.

Se hizo una asignación muestral de 17 encuestas de una población de 360 estudiantes de cuarto semestre de la carrera de administración de empresas correspondiente a la facultad de ciencias económicas de la ciudad de Tarija -Bolivia.

\section{RESULTADOS ALCANZADOS}

En la investigación se pudo encontrar los siguientes resultados que sirvió de referencia de acuerdo a la tabla y gráficos que se muestran a consideración:

Tabla 1: Planificación -organización y desarrollo de la materia

\begin{tabular}{|c|c|c|}
\hline $\begin{array}{c}\text { Materia } \\
\text { on mayor presencia) }\end{array}$ & $\begin{array}{c}\text { Alternativa de } \\
\text { respuestas }\end{array}$ & $\begin{array}{c}\text { Valor absoluto } \\
\text { (estudiantes) }\end{array}$ \\
\hline
\end{tabular}

\begin{tabular}{lccc}
\hline Matemática Financiera & Siempre & 6 & $35 \%$ \\
Conducta del Consumidor & Frecuentemente & 3 & $18 \%$ \\
Metodología de la Investigación & A veces & 8 & $47 \%$
\end{tabular}




\begin{tabular}{cccc}
\hline Comunicación Oral & Casi nunca & 0 & $0 \%$ \\
Muestreo estadístico & Nunca & 0 & $0 \%$ \\
\hline \multirow{2}{*}{ TOTAL } & & 17 & $100 \%$ \\
\hline
\end{tabular}

Fuente: Encuesta aplicada a estudiantes de tercer año de Administración de Empresas.

Figura 1: Conocimiento de los temas que expuso el docente

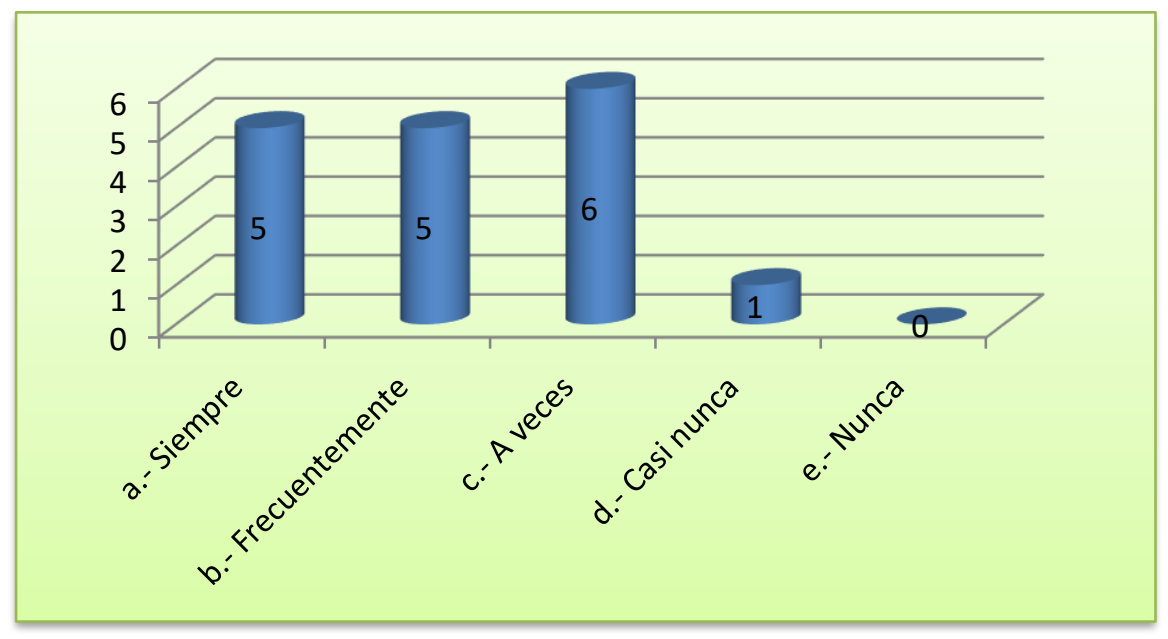

Fuente: Datos de encuesta aplicada a estudiantes de tercer año

Según la figura 1, el 29\% afirma que siempre el docente tiene conocimiento de los temas que exponen en el aula lo hacen frecuentemente, $35 \%$ piensan que solo lo hacen a veces y $6 \%$ que no lo hacen casi nunca demostró el conocimiento de los temas que expuso lo cual es un factor importante en la planificación y organización de la cátedra.

Figura 2: Las clases fueron amenas e interesantes 


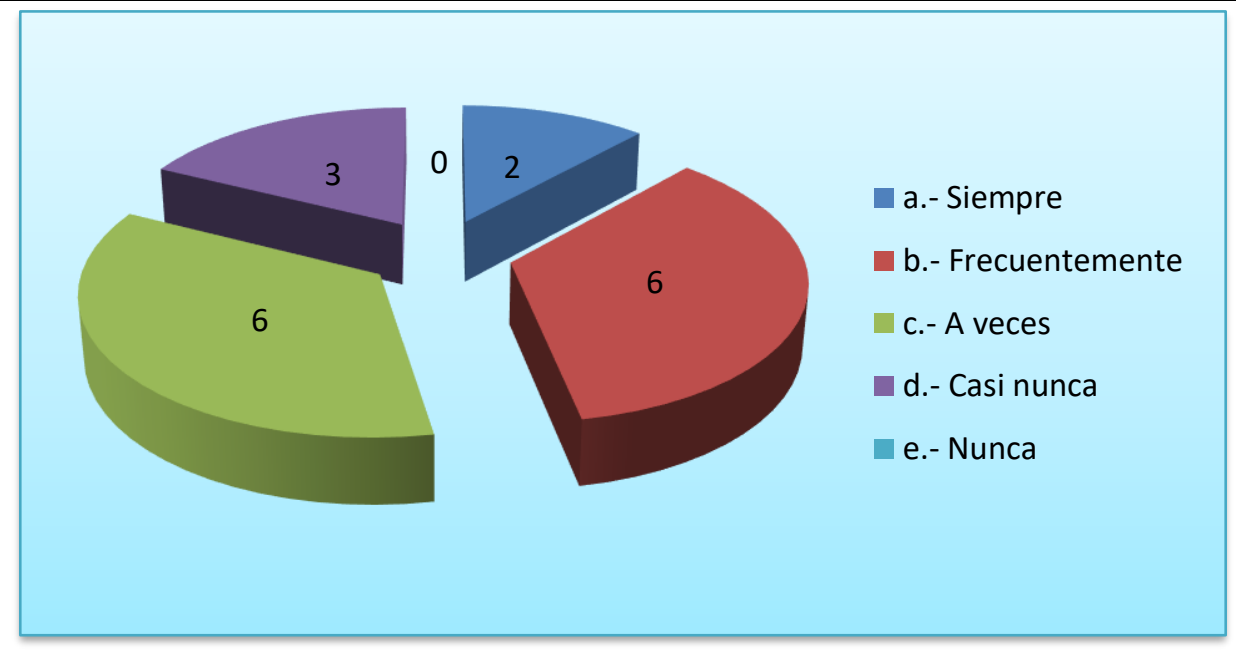

Fuente: Datos de encuesta aplicada a estudiantes de tercer año

Según los datos proporcionados por estudiantes el 12\% afirma que siempre lo hacen, 35\% dice que lo hacen frecuentemente, 35\% piensan que solo lo hacen a veces y $18 \%$ que no lo hacen casi nunca sus clases amenas e interesantes, lo que permite inferir que se deben mejorar las estrategias didácticas.

Figura 3: El docente se preocupó porque los alumnos entiendan lo explicado en clases

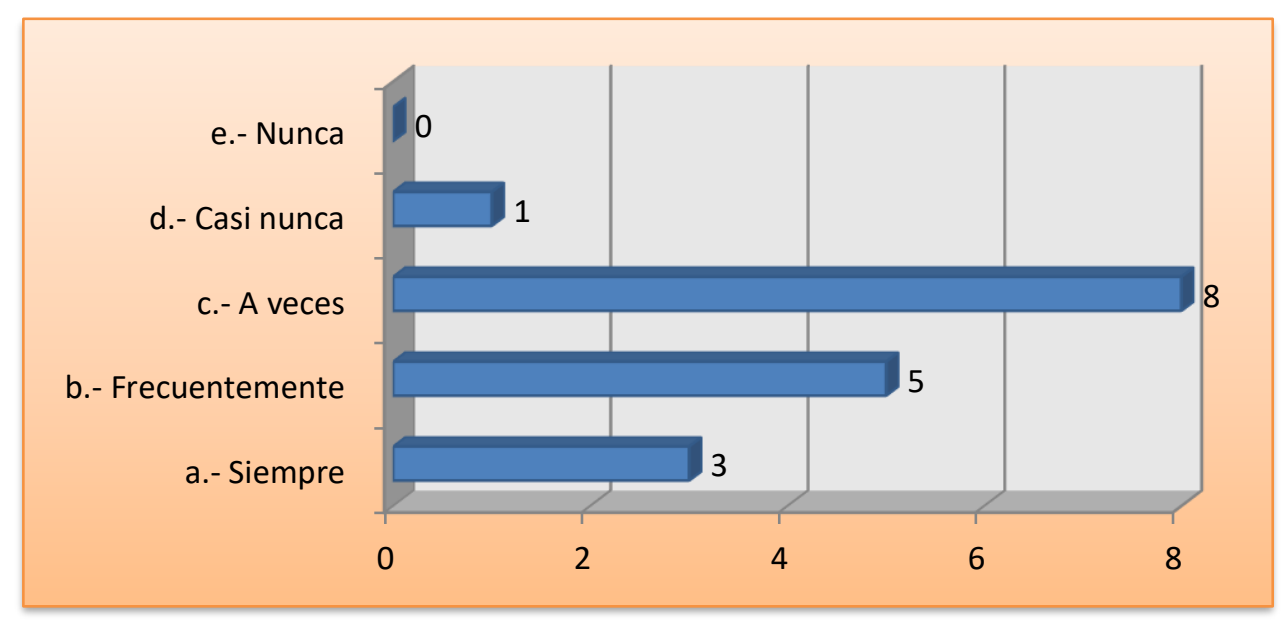

Fuente: Datos de encuesta aplicada a estudiantes de tercer año

Según la figura 3, El 18\% afirma que siempre lo hacen, $29 \%$ dice que lo hacen frecuentemente, $47 \%$ piensan que solo lo hacen a veces y $6 \%$ que no lo hacen casi nunca. una retroalimentación efectiva en el proceso de enseñanza de cada asignatura.

Figura 4: El profesor permitió efectuar preguntas durante las clases 


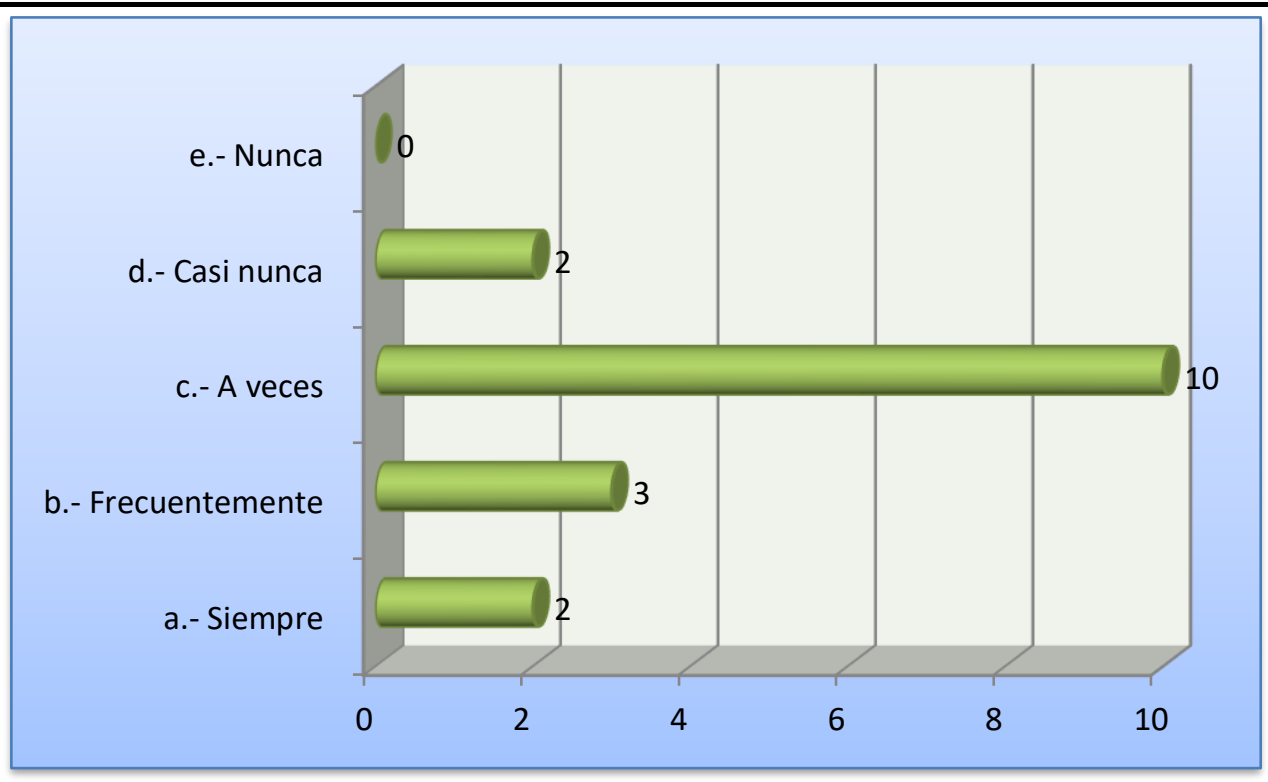

Fuente: Datos de encuesta aplicada a estudiantes de tercer año

En función a los datos proporcionados 12\% afirma que siempre lo hacen, 18\% dice que lo hacen frecuentemente, 59\% piensan que solo lo hacen a veces y $12 \%$ que no lo hacen casi nunca, el docente permite hacer preguntas en clases un aspecto importante es de generar un espacio de participación efectiva por parte de los estudiantes permitiendo un mejor flujo de información en el aula.

Figura 5: El docente cumplió con el programa de su materia

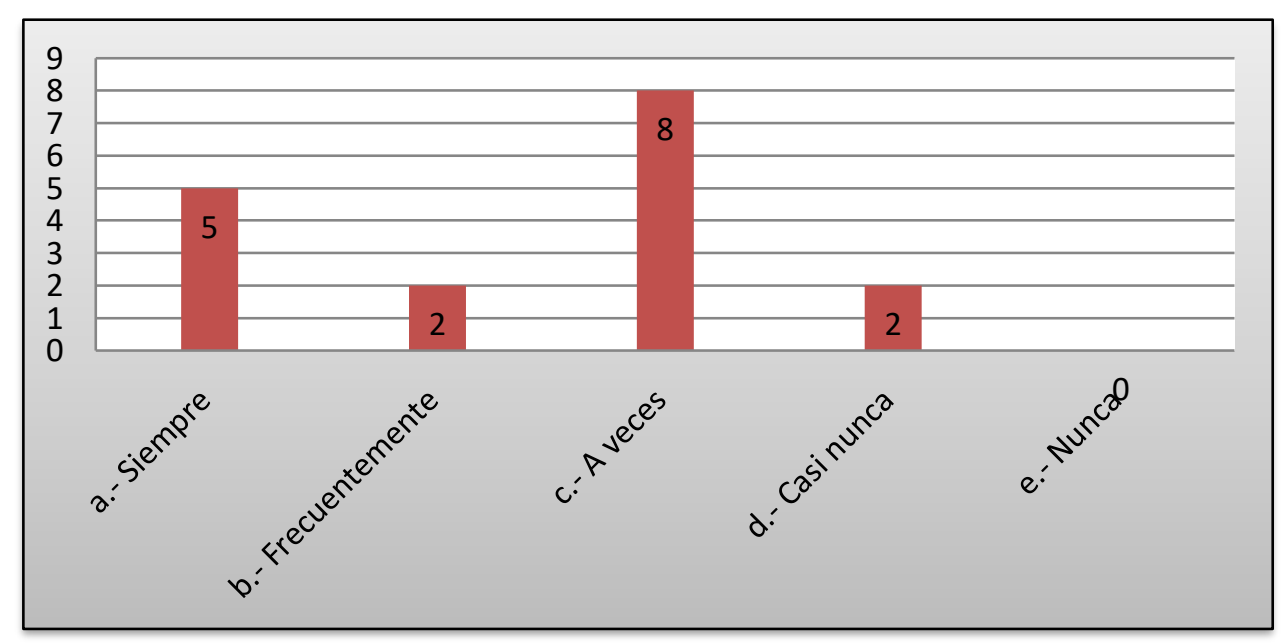

Fuente: Datos de encuesta aplicada a estudiantes de tercer año

El 29\% afirma que siempre lo hacen, $12 \%$ dice que lo hacen frecuentemente, $47 \%$ piensan 
que solo lo hacen a veces, $12 \%$ que no lo hacen casi nunca, el docente completo su plan docente permitiendo deducir que este factor es importante porque permitirá poder cumplir con los objetivos de aprendizaje en las diferentes asignaturas.

Figura 6: El docente oriento en la realización de los trabajos prácticos

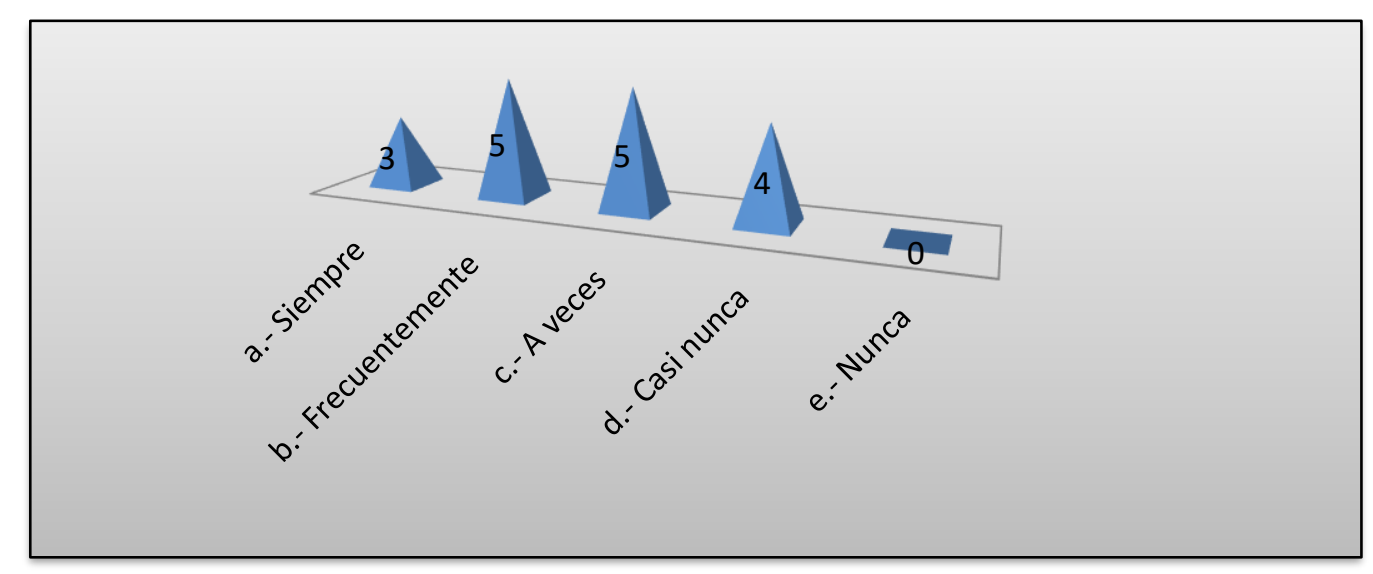

Fuente: Datos de encuesta aplicada a estudiantes de tercer año

Según datos proporcionados por los estudiantes el 18\% afirma que siempre lo hacen, 29\% dice que lo hacen frecuentemente, $29 \%$ piensan que solo lo hacen a veces y $24 \%$ que no lo hacen casi nunca el docente oriento en la realización de los trabajos prácticos.

Figura 7: Relaciono el tema con otras materias o con problemas de la realidad el docente

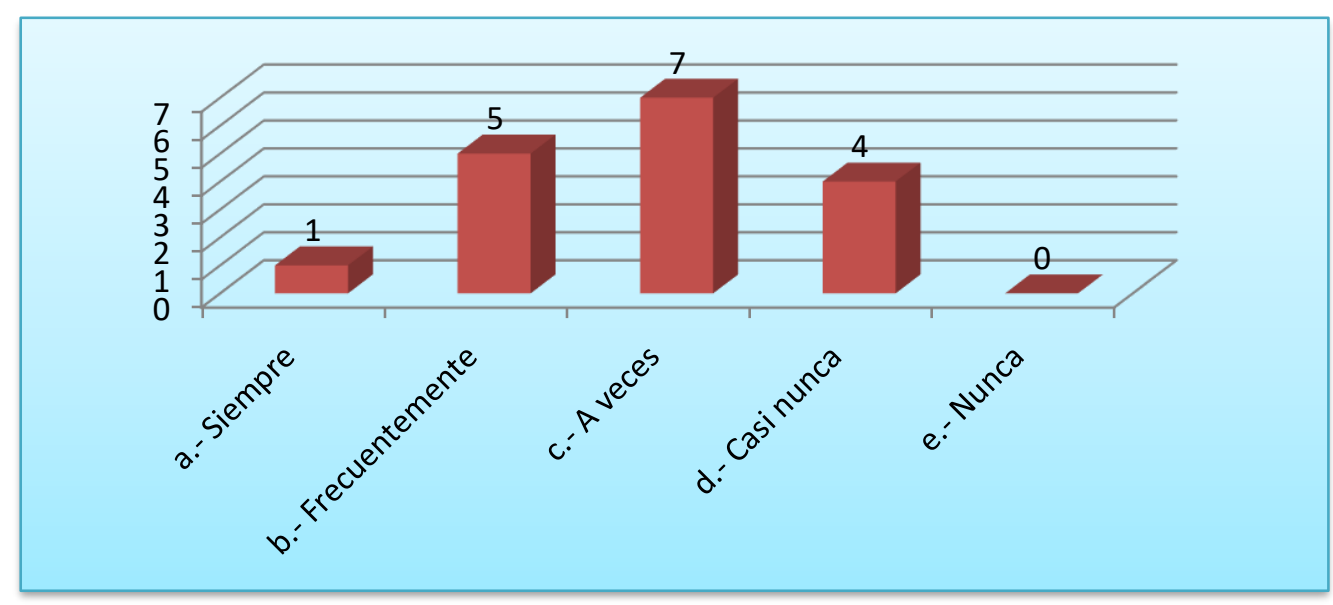

Fuente: Datos de encuesta aplicada a estudiantes de tercer año

El 6\% afirma que siempre lo hacen, 29\% dice que lo hacen frecuentemente, $41 \%$ piensan que solo lo hacen a veces y $24 \%$ que no lo hacen casi nunca es importante poder mejorar este aspecto ya que por parte de los docentes que permitirá poder contextualizar de mejor manera su asignatura partiendo de ejemplos concretos que se dan en lo coyuntural en otras 
asignaturas y que se resalte su aplicabilidad en las demás asignaturas ya que estas deben contribuir a una formación integral.

Figura 8: El docente ofrece horas de consulta a los estudiantes

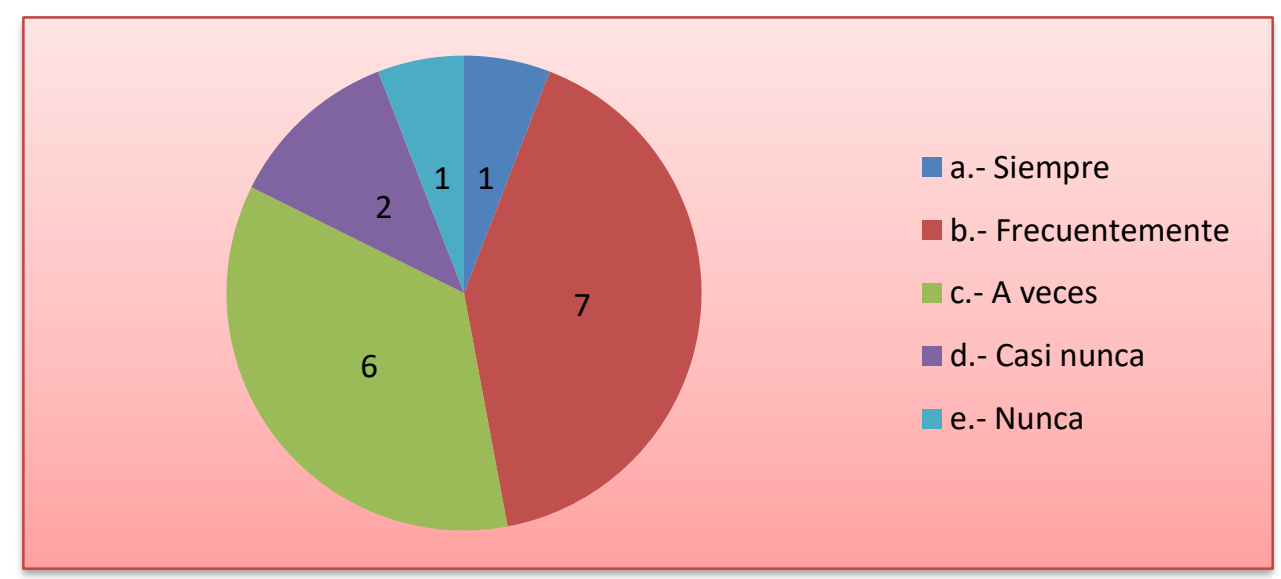

Fuente: Datos de encuesta aplicada a estudiantes de tercer año

El $6 \%$ afirma que siempre lo hacen, $41 \%$ dice que lo hacen frecuentemente, 35\% piensan que solo lo hacen a veces, $12 \%$ que no lo hacen casi nunca el poder ofrecer horas de consulta a los estudiantes en las asignaturas regentadas un aspecto importante a resaltar son las horas adicionales de consulta por parte de los docentes a los estudiantes en lo que respecta a los trabajos en aula y extra aula.

Figura 9: El docente promovió la organización de equipos de trabajo en el aula

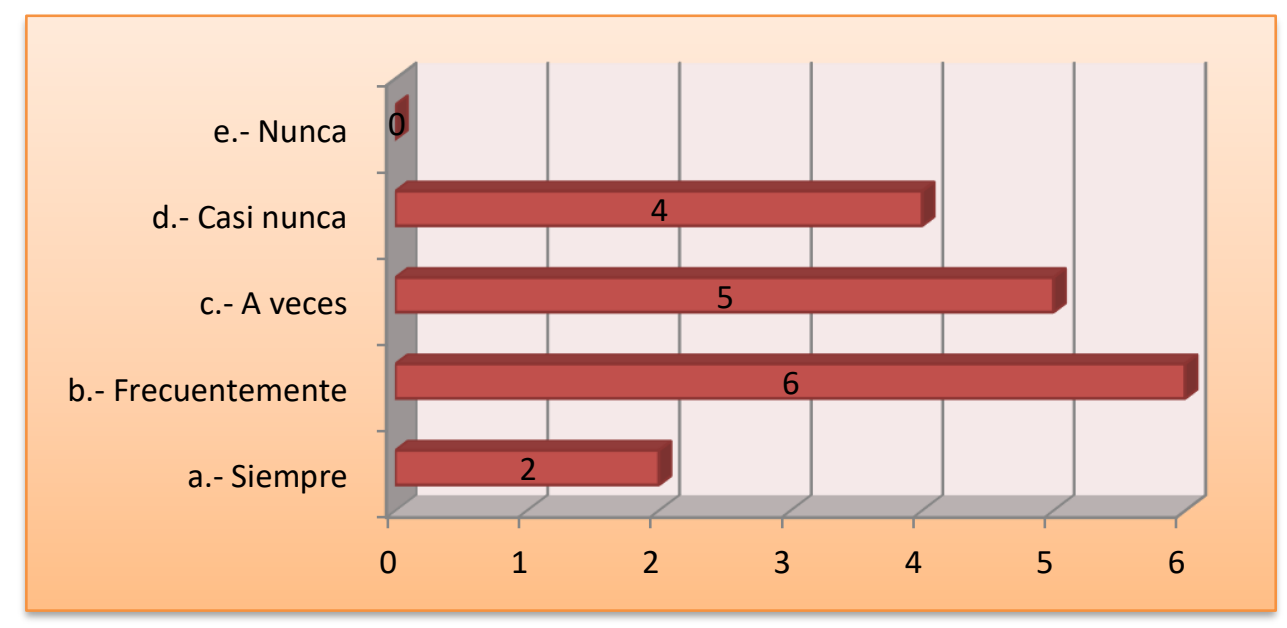

Fuente: Datos de encuesta aplicada a estudiantes de tercer año

El 12\% afirma que siempre lo hacen, 35\% dice que lo hacen frecuentemente, 29\% piensan 
que solo lo hacen a veces, $24 \%$ que no lo hacen casi nunca el poder promover equipos de trabajos en el aula lo cual denota una competencia importante que se debe generar en los estudiantes que es el trabajo en equipo experimentado en el aula para luego poder replicar en las empresas un factor importante de destacar.

Figura 10: La forma de evaluación del docente te parece adecuada

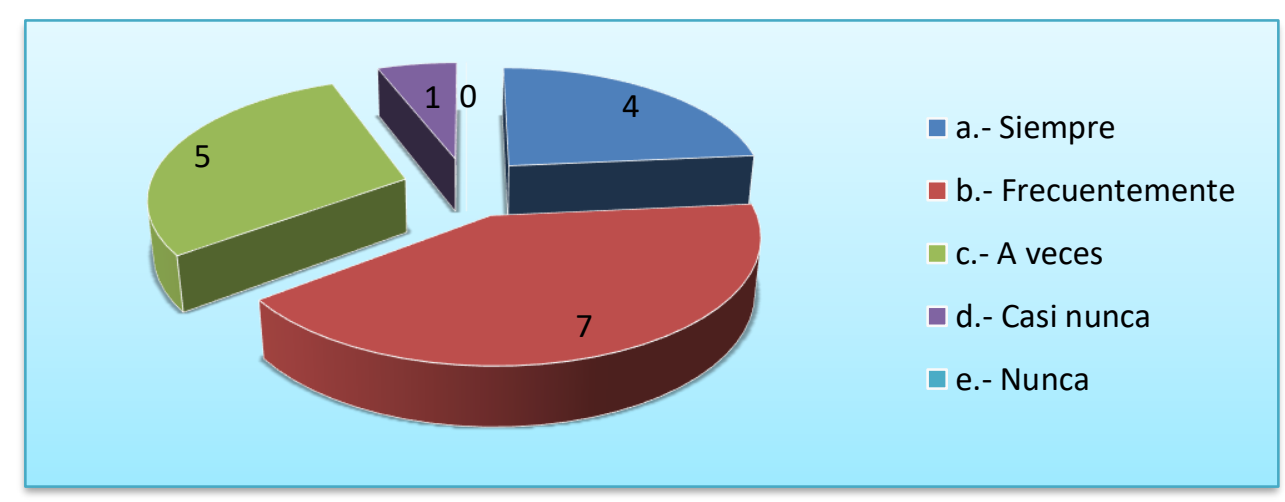

Fuente: Datos de encuesta aplicada a estudiantes de tercer año

El 24\% afirma que siempre lo hacen, $41 \%$ dice que lo hacen frecuentemente, 29\% piensan que solo lo hacen a veces, $6 \%$ que no lo hacen casi nunca este aspecto es importante ya que permite valorar contenidos que se desarrollan en el aula lo que permite inferir que el mayor porcentaje de docentes lo realiza en función a los contenidos de cada asignatura.

Figura 11: Las preguntas de los exámenes fueron referidas a temas avanzados

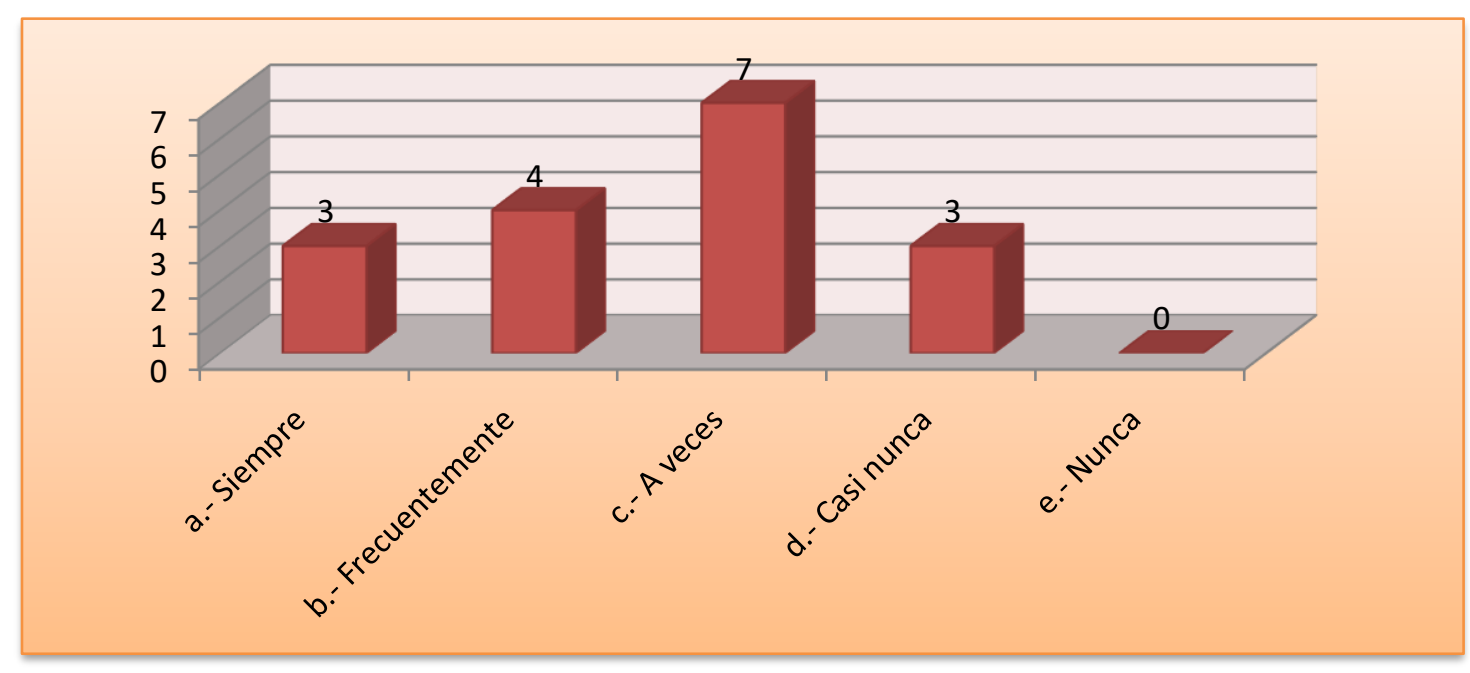

Fuente: Datos de encuesta aplicada a estudiantes de tercer año

Según datos proporcionados por estudiante el 18\% afirma que siempre es así, 24\% dice 
que lo es frecuentemente, $41 \%$ piensan que solo lo es a veces, $18 \%$ que no lo es casi nunca las preguntas fueron realizadas en función a los temas avanzados lo que muestra que la mayor parte de docentes realizan en sus preguntas en función a los temas avanzados.

Figura 12: Los exámenes fueron de razonamiento y no memorismo

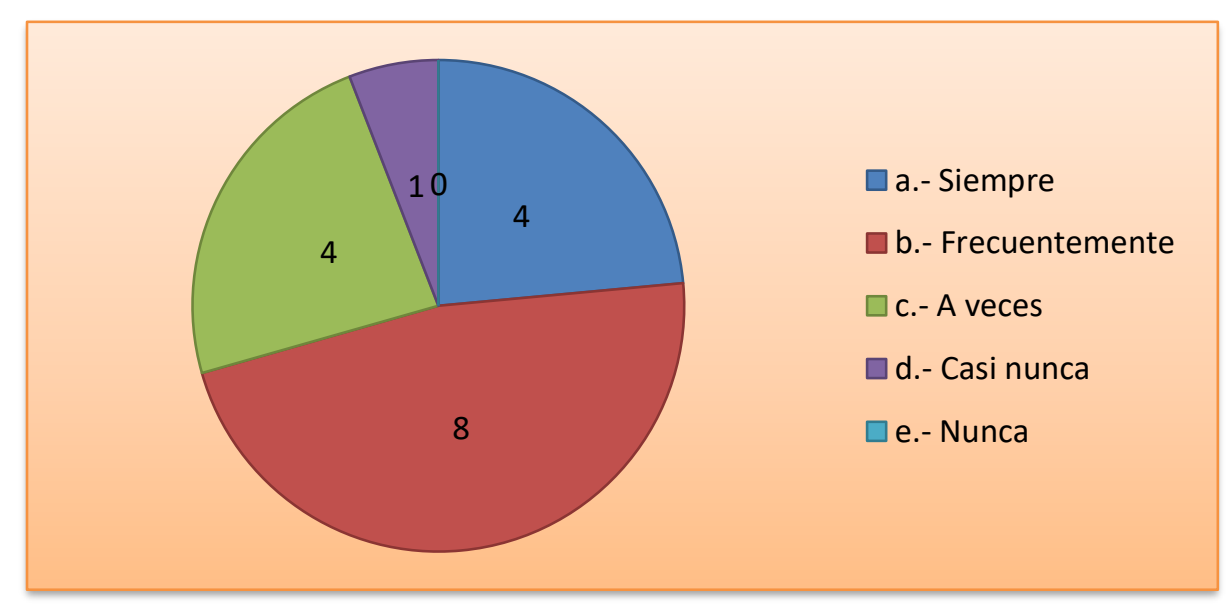

Fuente: Datos de encuesta aplicada a estudiantes de tercer año

El 24\% afirma que siempre es así, $47 \%$ dice que lo es frecuentemente, $24 \%$ piensan que solo lo es a veces, $6 \%$ que no lo es casi nunca las preguntas fueron de razonamiento y no memorístico lo que permite deducir que el diseño de las pruebas evaluativas fueron de razonamiento un aspecto importante es generar un análisis crítico por parte de los estudiantes hacia su desempeño profesional.

Figura 13: El docente mostro oportunamente los exámenes a los estudiantes 


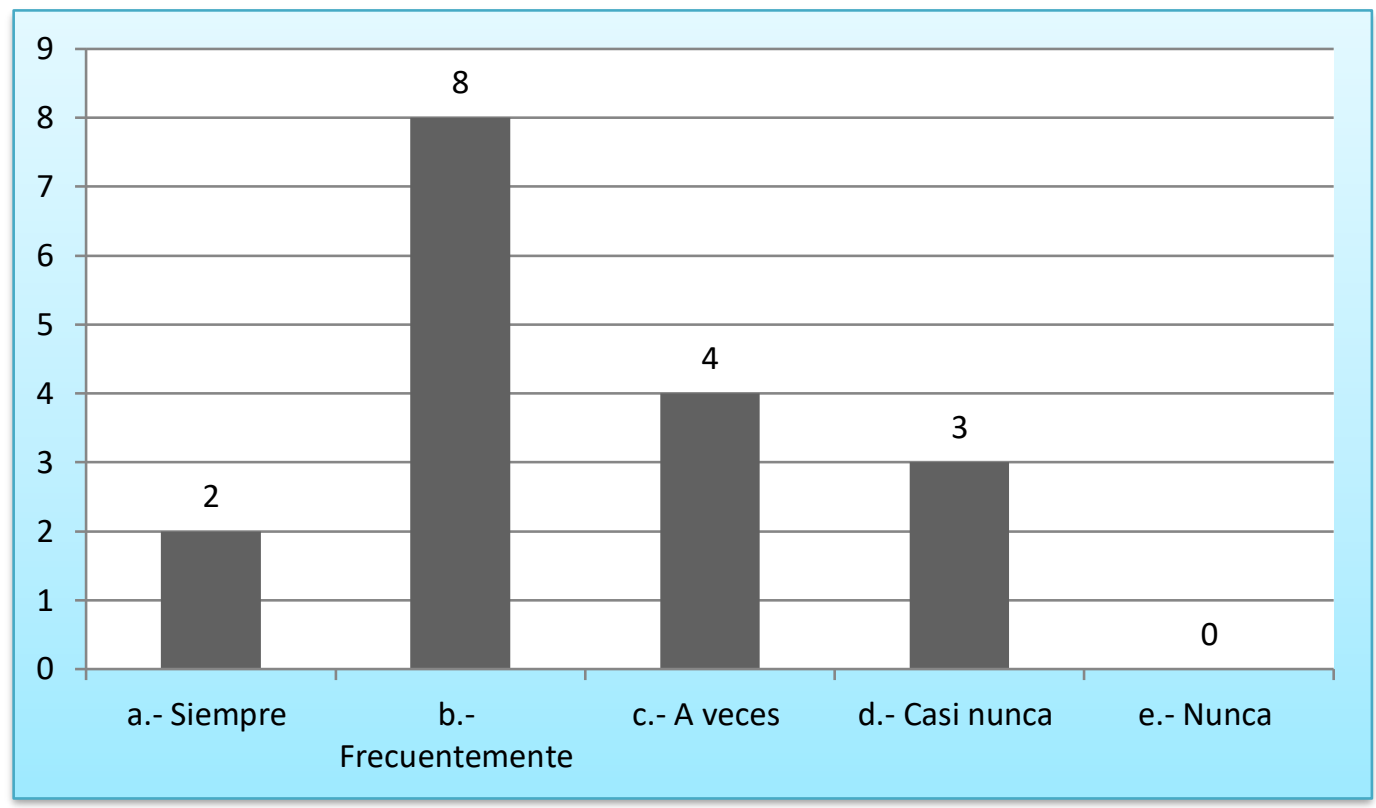

Fuente: Datos de encuesta aplicada a estudiantes de tercer año

El 12\% afirma que siempre lo hacen, $47 \%$ dice que lo hacen frecuentemente, $24 \%$ piensan que solo lo hacen a veces, $18 \%$ que no lo hacen casi nunca según reglamentos internos de la institución es poder mostrar y resolver a los estudiantes sus evaluaciones un aspecto importante de señalar.

Figura 14: El docente efectuó ampliaciones de temas no suficientemente comprendidos 


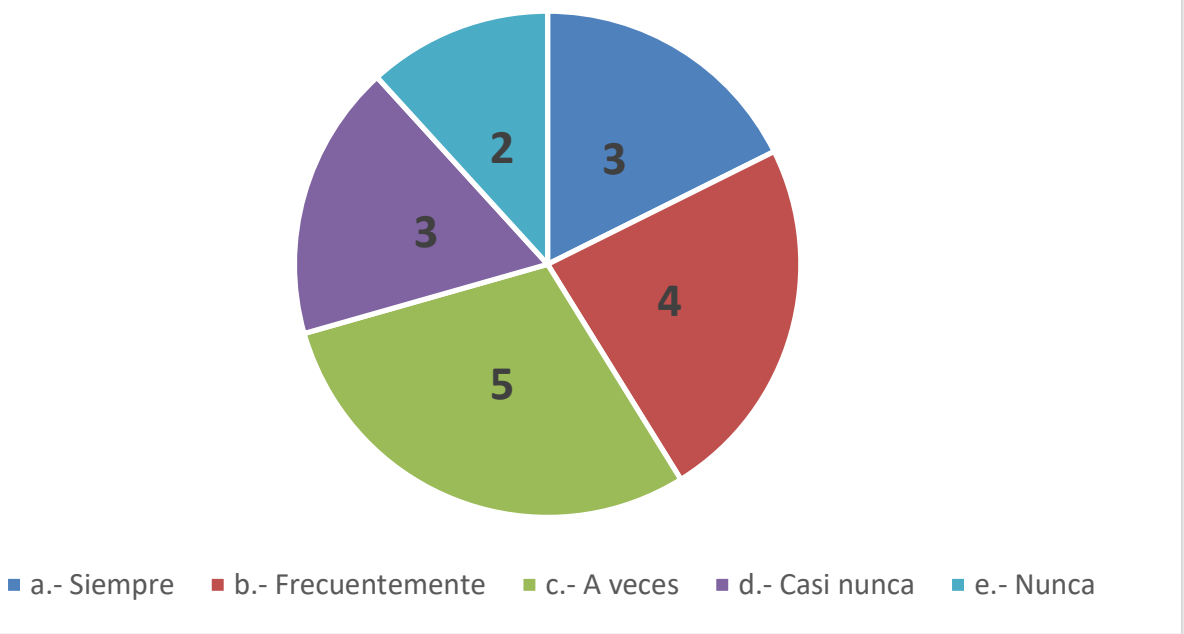

Fuente: Datos de encuesta aplicada a estudiantes de tercer año

El 18\% afirma que siempre lo hacen, 24\% dice que lo hacen frecuentemente, $29 \%$ piensan que solo lo hacen a veces, $18 \%$ que no lo hacen casi nunca y $12 \%$ opinan que nunca lo hacen, el poder responder a cuestionarte generados en los temas avanzados es relevante poder inferir en este aspecto ya que se podrá generar espacios de dialogo en el aula.

\section{Figura 15: Atendió el docente aclaraciones que solicito el alumno sobre sus exámenes}

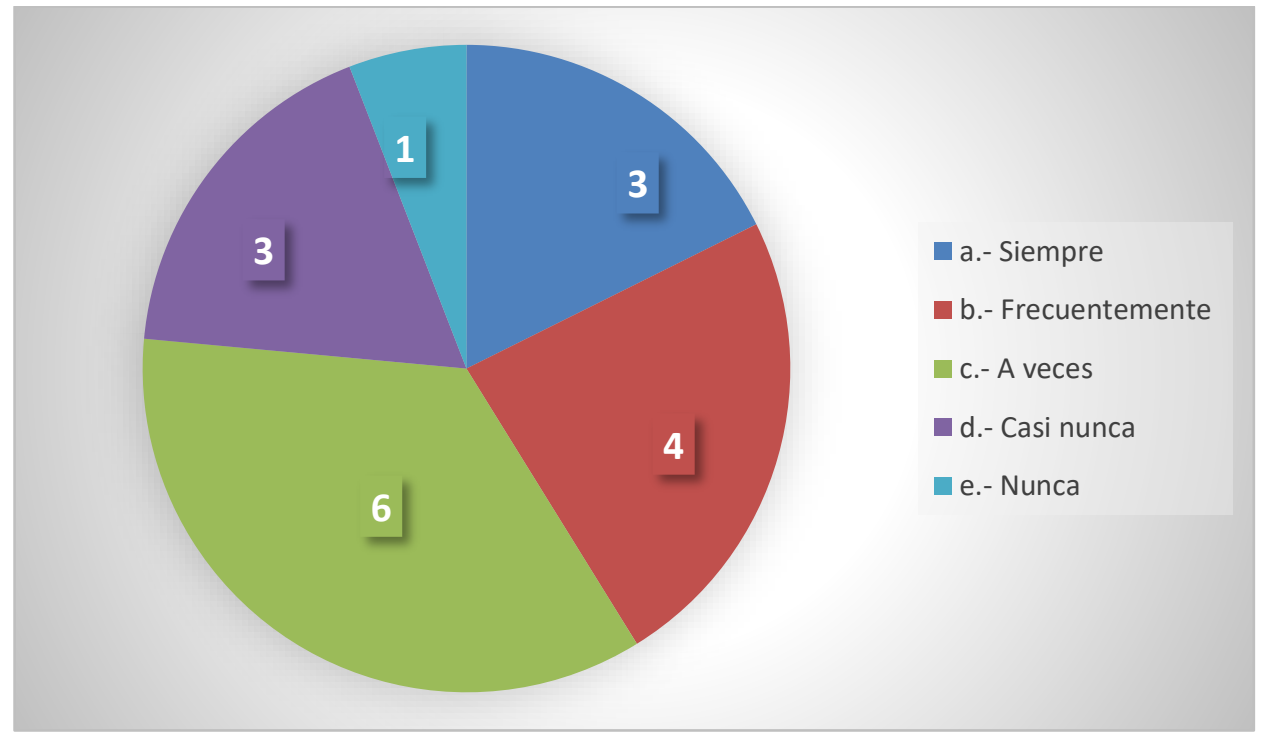

Fuente: Datos de encuesta aplicada a estudiantes de tercer año

Según datos proporcionados el 18\% afirma que siempre lo hacen, 24\% dice que lo hacen frecuentemente, $35 \%$ piensan que solo lo hacen a veces, $18 \%$ que no lo hacen casi nunca y $6 \%$ opinan que nunca lo hace el poder realizar aclaraciones sobre las evaluaciones. 
Figura 16: El docente evalúa las prácticas, tareas y trabajos de manera oportuna

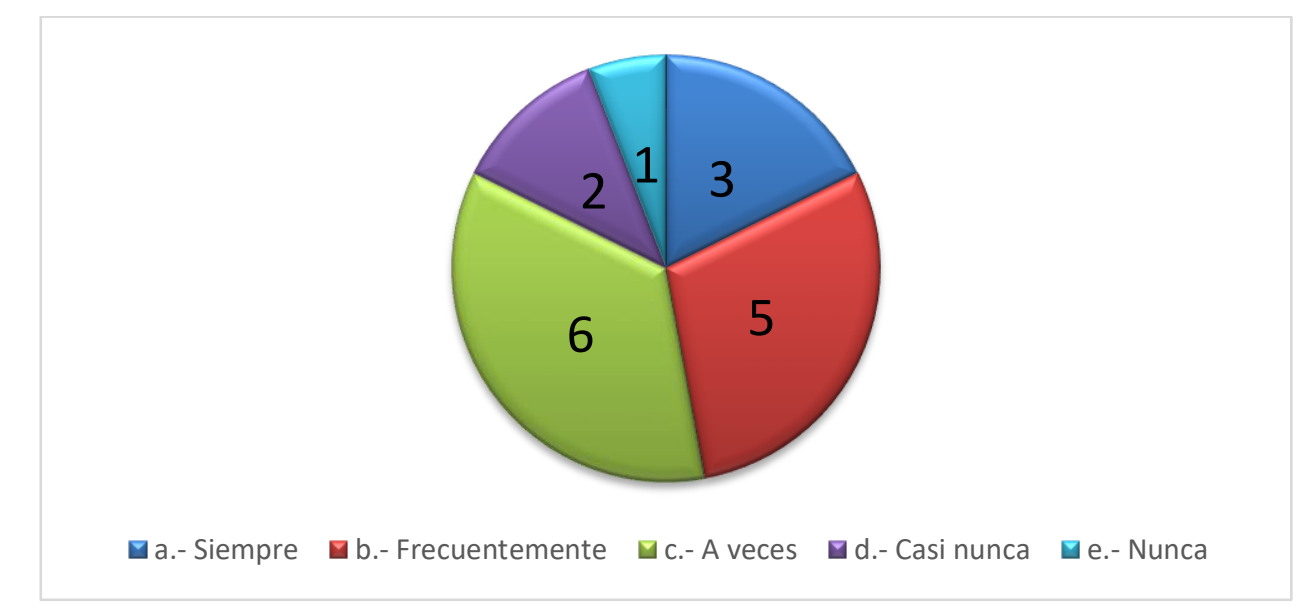

Fuente: Datos de encuesta aplicada a estudiantes de tercer año

El 18\% afirma que siempre lo hacen, 29\% dice que lo hacen frecuentemente, 35\% piensan que solo lo hacen a veces. $12 \%$ que no lo hacen casi nunca y $6 \%$ opinan que nunca lo hacen la mayor parte de docentes realizan la evaluación de prácticas y otros trabajos generados en el aula.

Figura 17: El docente realiza la autoevaluación (Recibe sugerencias para mejorar el desempeño de su materia)

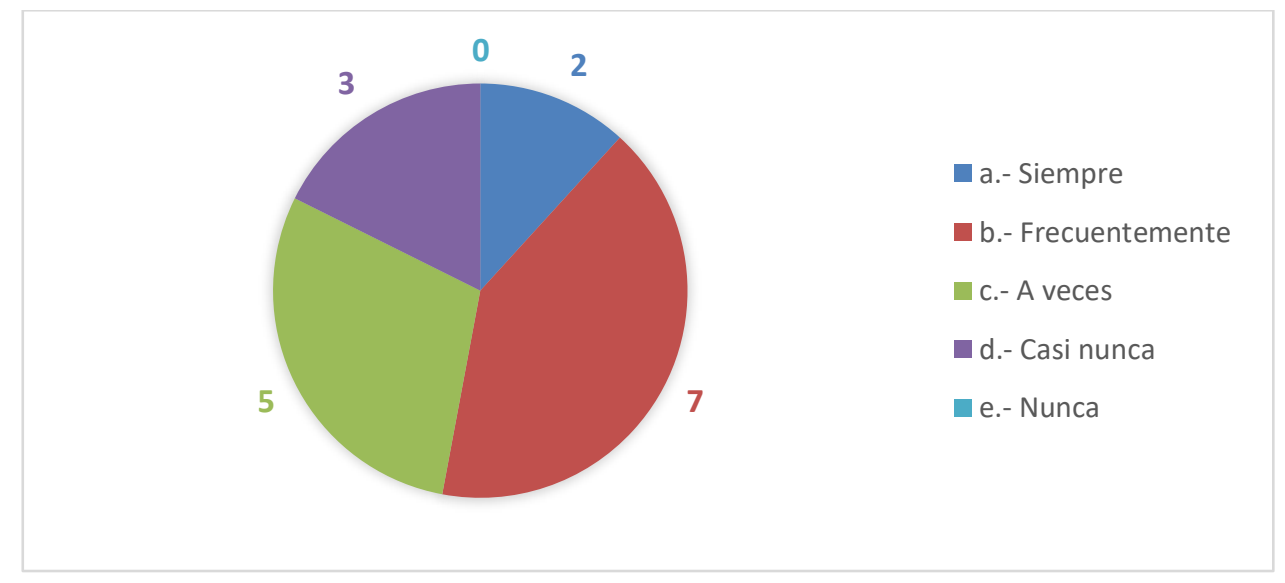

Fuente: Datos de encuesta aplicada a estudiantes de tercer año

Según datos obtenidos el 12\% afirma que siempre lo hacen, $41 \%$ dice que lo hacen frecuentemente, 29\% piensan que solo lo hacen a veces, $18 \%$ que no lo hacen casi nunca realiza la autoevaluación de su asignatura que regento un aspecto relevante es generar la autoevaluación de su asignatura permitiendo mejorar su desempeño y realizar ajustes en la 
misma gran parte de los docentes no lo están utilizando de manera oportuna lo que permite poder trabajar más aun este aspecto.

Figura 18: El docente realiza la Coevaluación y la Heteroevaluación

(Evaluación cruzada de actividades)

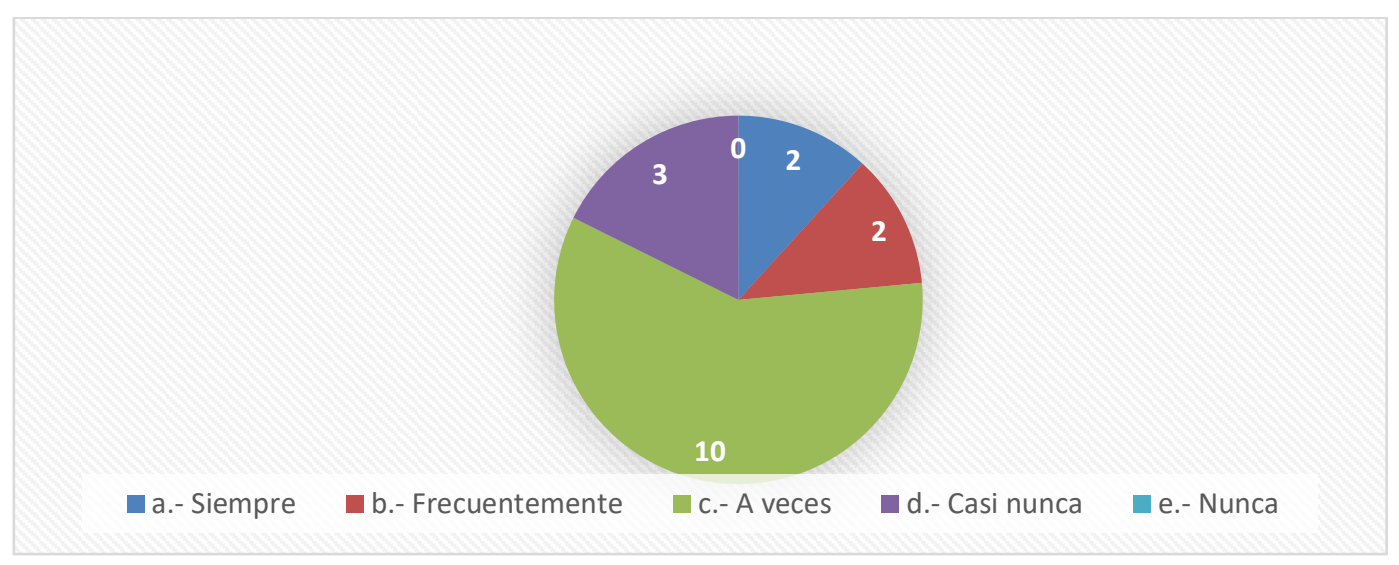

Fuente: Datos de encuesta aplicada a estudiantes de tercer año

El 12\% afirma que siempre lo hacen,12\% dice que lo hacen frecuentemente, 59\% piensan que solo lo hacen a veces, $18 \%$ que no lo hacen casi nunca este aspecto también se debería trabajar más ya que el permitir ajustar más allá contenidos no solo queda en un rediseño, sino que el poder involucrar a otros actores en el proceso de formación.

Figura 19: En el desarrollo de clases utiliza medios didácticos de apoyo (revistas, libros, apuntes, o cualquier otro) para ayudar a entender lo explicado

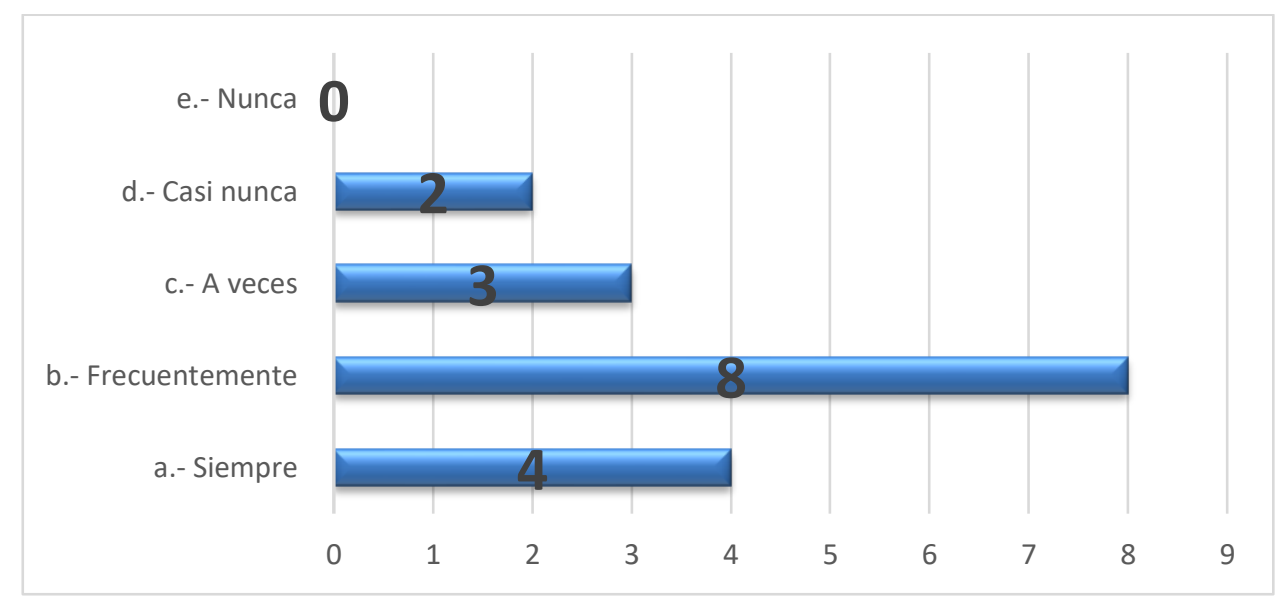

Fuente: Datos de encuesta aplicada a estudiantes de tercer año 
El 24\% afirma que siempre lo hacen, $47 \%$ dice que lo hacen frecuentemente, 18\% piensan que solo lo hacen a veces. , 12\% que no lo hacen casi nunca, no cabe duda la importancia de poder utilizar los medios didácticos en sus asignaturas lo cual se deberá trabajar más este aspecto.

Figura 20: En el desarrollo de sus clases se usó al menos la pizarra u otro medio, data Show

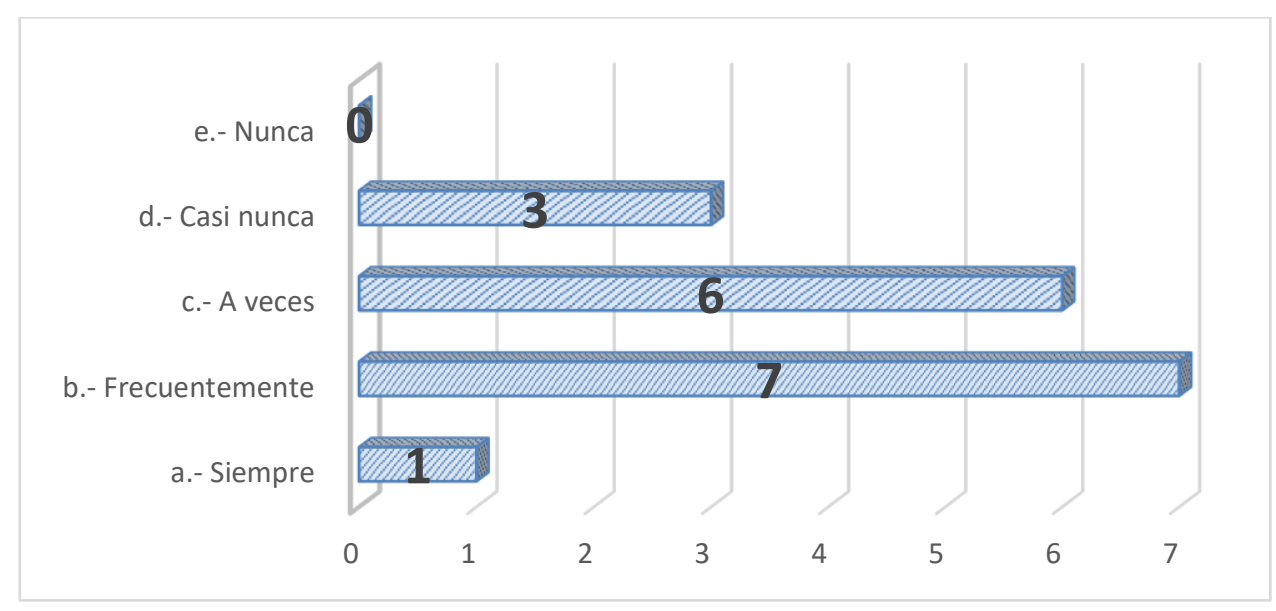

Fuente: Datos de encuesta aplicada a estudiantes de tercer año

El $6 \%$ afirma que siempre lo hacen, $41 \%$ dice que lo hacen frecuentemente, 35\% piensan que solo lo hacen a veces, $18 \%$ que no lo hacen casi nunca. Utiliza un medio tecnológico como ser el data show existe un porcentaje importante de docentes que todavía no están utilizando los recursos tecnológicos que existen en el medio lo cual se deberá trabajar en capacitar más en su utilización adecuada en aula.

Figura 21: La bibliografía que el docente utilizo en su materia como ser libros, fotocopias u otros, existían en nuestro medio

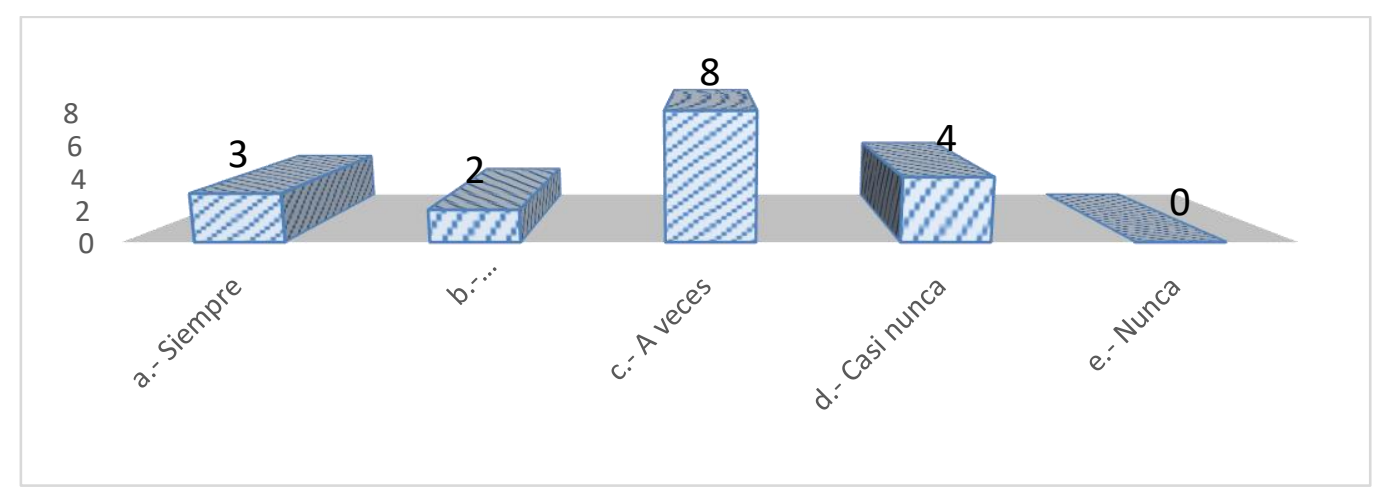

Fuente: Datos de encuesta aplicada a estudiantes de tercer año 
El 18\% afirma que siempre lo hacen, $12 \%$ dice que lo hacen frecuentemente, $47 \%$ piensan que solo lo hacen a veces, $24 \%$ que no lo hacen casi nunca un porcentaje mayor de docentes utilizan materiales bibliográficos actuales lo cual es importante destacar ya que permite estar al día en este recurso importante en la academia.

Figura 22: El docente asistió a clases y cumplió con el horario

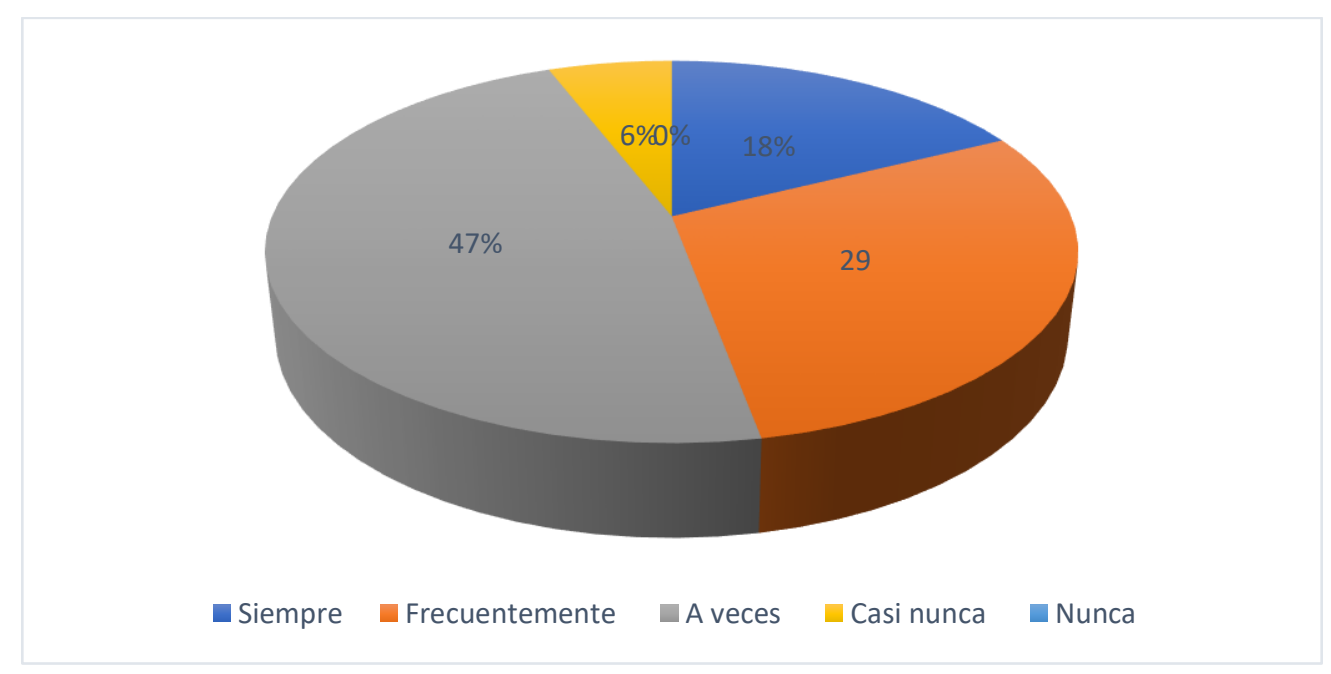

Fuente: Datos de encuesta aplicada a estudiantes de tercer año

El 47\% sostiene que lo hacen frecuentemente, 29\% piensan que solo lo hacen a veces, $18 \%$ que no lo hacen casi nunca y $6 \%$ opinan que nunca lo hacen, lo que permite se puede deducir que el docente se siente comprometido a cumplir su carga horaria lo cual es un aspecto importante a destacar en la labor formativa

Figura 23: El docente fomenta el emprendedurismo entre los estudiantes

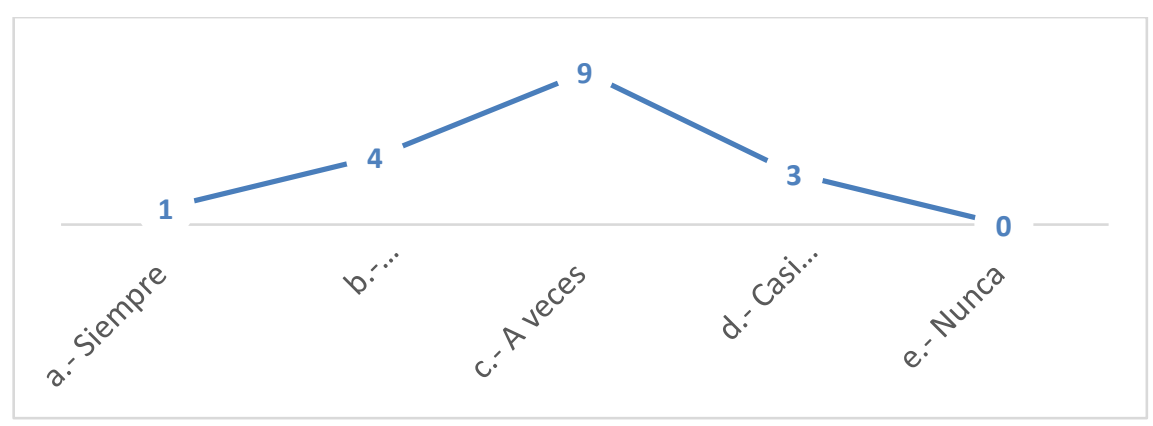

Fuente: Datos de encuesta aplicada a estudiantes de tercer año

El $6 \%$ afirma que siempre lo hacen, el $24 \%$ dice que lo hacen frecuentemente, $53 \%$ piensan 
que solo lo hacen a veces, $18 \%$ que no lo hacen casi nunca y $\%$ opinan que nunca lo hacen, lo que lleva a deducir que los docentes en un gran porcentaje fomentan al emprendedurismo a sus estudiantes lo cual es importante ya que en la actualidad no solo la formación debe orientarse a formar empleados sino fortalecer la formación hacia el emprendedurismo lo que permitirá generar fuentes de trabajo.

\section{DISCUSION}

El estudio comprende una estructura, que abarca tanto aspectos generales y específicos de la labor formativa dentro del marco del Proceso Enseñanza Aprendizaje cuyo proceso se concreta en una situación creada para que el estudiante aprenda a aprender. Se constituyen en un proceso dialéctico donde se crean situaciones para que el sujeto se apropie de las herramientas que le permitan operar con la realidad y enfrentar al mundo con una actitud científica, personalizada y creadora. En ello desempeña un importante papel el rol que desarrolla el profesor (Kursanov.2000).

La didáctica de la enseñanza superior (Escudero, 2006; Rué, 2007; Fuentes, 2009) le proporciona al docente diferentes tipos de clases o formas de docencia, las que deben ser planificadas teniendo en cuenta los elementos ya mencionados. Las clases teórica presentan generalizaciones sobre el tema tratado. En esta parte de la clase el docente sintetiza los aspectos fundamentales, en correspondencia con los objetivos propuestos. Hace énfasis en lo que aporta lo estudiado al futuro desempeño profesional de los estudiantes. Realiza interrogantes que le permiten obtener información sobre la asimilación de los conocimientos expuestos; en consecuencia, precisa lo que se requiera, para ello puede emplear organizadores gráficos (Ontoria et al., 2006).

Según los resultados obtenidos en la investigación en el aspecto de planificaciónorganización y desarrollo de la materia, marcan que hay afirmaciones más que desviaciones de las respuestas a los cuestionarios aplicado, los mismos indican que los docentes cumplen frecuentemente con el desenvolvimiento y organización de las materias existentes en el plan de estudios, lo cual muestra una planificación formal anticipada de actividades por parte de los docentes. Es necesario que el docente, al preparar la clase práctica, a partir de los 
objetivos del programa y de las características de sus estudiantes, eleve de manera gradual la complejidad de las habilidades necesarias para solucionar las tareas que exigen la aplicación de los conocimientos adquiridos.

De esta forma, puede ir logrando el tránsito de los alumnos de la dependencia a la independencia, dando al aprendizaje un carácter desarrollador (Castellanos et al., 2002).

Es necesario preparar a los estudiantes, de manera paulatina, a partir del modelo que transmita el docente, para que con objetividad valoren los logros alcanzados, en su trabajo y en el de sus condiscípulos, a sabiendas de que siempre pueden superarse. Además, deben educarse para que sean capaces de reconocer deficiencias, siempre con el ánimo que contribuir a su mejora. El docente debe realizar la heteroevaluación (Sanmartí, 2007) al ofrecer sus criterios sobre lo logrado y señalar las medidas necesarias para realizar el seguimiento al aprendizaje de los alumnos, de manera diferenciada.

Asimismo, las afirmaciones respecto a la manera en que evalúan y como se desenvuelven en sus áreas respectivas los docentes, tienen muchas falencias y son poco claras. Se puede afirmar que la evaluación que planteamos es formativa, es decir forma parte de un proceso y permite la mejora a lo largo del mismo. Estamos por tanto en la línea argumentativa de Rodríguez e Ibarra (2011) que defienden que la evaluación debe ser una oportunidad de aprendizaje orientada a mejorar y promover aprendizajes significativos y que actualmente en el sistema universitario no se realiza pues se sigue poniendo el énfasis en el trabajo del profesorado antes que en el aprendizaje de los estudiantes.

Entre los resultados en cuanto a la metodología de evaluación del proceso de enseñanza aprendizaje, se ha observado que en base a los datos recopilados que los estudiantes han respondido en promedio con un a veces, y frecuentemente realizan un sistema de evaluación claro en sus asignaturas que imparten, en lo referente a las preguntas empleadas en las pruebas implementadas fueron claras y referidas a los temas avanzados en clase, lo cual permite tener una lógica en lo que se avanza con lo que se pregunta en las pruebas de evaluación. Por el grado de satisfacción de alumnado, expertos y profesorado, los resultados avalan que se ha avanzado en varias direcciones claves para una enseñanza mucho más 
activa, menos la memorizadora más centrada en tareas del alumnado y, lo que es de destacar, con un sistema de evaluación que no precisa la presencialidad. De modo que se confirman las aportaciones Sloep y Berlanga (2011), que proponen la posibilidad de crear redes de aprendizaje más allá de las fronteras entre las universidades. La información también permitió observar que los docentes, solo a veces o casi nunca realizan ampliaciones de temas no comprendidos por los alumnos, también a veces atienden aclaraciones sobre las evaluaciones dadas por los alumnos, las evaluaciones son corregidas y entregadas frecuentemente y a veces en su debido tiempo para que los estudiantes puedan verlo y así poder optar por reclamar si tuvieran algún tipo de error que quizás el docente no tomo en cuenta, lo cual permite una comunicación más de carácter horizontal entre el docente -alumno permitiendo frecuentemente también evaluar prácticas, tareas $u$ otros trabajos de manera oportuna; se notó que los docentes también no realizan una autoevaluación de su materia al final de cada semestre académico y que a veces o pocas veces realizan una evaluación en sus asignaturas para así tener otra perspectiva dentro del proceso de enseñanza y aprendizaje.

En el Uso de Recursos didácticos, se obtuvo como resultados que frecuentemente o en su mayoría los docentes recurren al uso de medios didácticos para desarrollar de mejor manera su clase, a veces no solo se usa el pizarrón sino también aparatos tecnológicos como data show y tics, Las TIC, junto con la formación profesional docente, propician el cambio al mejorar el desempeño de los estudiantes, promover el trabajo colaborativo y aumentar el desempeño laboral (Unesco 2008).

Así mismo fuera de poder implementar las TICs, en los espacios de enseñanza los docentes en la mayoría de los casos toman como ejemplo situaciones reales, es decir que se encuentren en nuestro medio contextualizándolas para poder ser más objetivos. Respecto a la bibliografía que utilizan y facilitan los docentes para la enseñanza de sus materias se pudo ver que frecuentemente se utilizan libros, fotocopias u otros, existentes en nuestras bibliotecas y en nuestro medio; en algunos casos dicha bibliografía es facilitada por los docentes cuando el alumno lo requiere y no siempre es bibliografía propia, sino que los docentes también que frecuentemente motivan a los estudiantes a utilizar otros medios de investigación o fuentes de información complementarias a los libros o textos cursados de la 
asignatura que regentan.

Finalmente, en el aspecto de asistencia se evidencio un cumplimiento a sus actividades académicas y están cumpliendo con los horarios asignados, frecuentemente el docente demuestra interés y tiene la voluntad para apoyar a los estudiantes en el proceso de aprendizaje; otro aspecto para valorar en la labor formativa es el fomento al espíritu emprendedor hacia los los estudiantes. Así también se observó que los docentes no siempre fomentan valores ético-morales dentro de las aulas lo cual se deberá fortalecer para poder formar profesionales con valores integrales que contribuya a la solución de problemas del contexto con pensamiento altamente crítico, demostrando en el comportamiento institucional un ambiente adecuado de trabajo.

\section{CONCLUSIONES}

Entre las conclusiones del presente se puede mencionar el siguiente:

En cuanto a la Planificación- Organización y desarrollo de la materia, no es desarrollada siempre de manera ordenada sin embargo se observó que si frecuentemente se realizan trabajos prácticos grupales de trabajo en los cuales también se enseña lo que es trabajo en equipo.

Respecto a las estrategias de evaluación del proceso de enseñanza aprendizaje, la mayoría cree que es aceptable la manera de enseñar de los docentes, pero las evaluaciones no son consideradas de temas avanzados o temas que no están bastante claros para el alumno.

En el uso de recursos didácticos, se obtuvo como resultados que frecuentemente o en su mayoría los docentes recurren al uso de medios didácticos para desarrollar de mejor manera su clase, a veces no solo se usa el pizarrón sino también aparatos tecnológicos como data show y otras TICs.

La bibliografía que poseen los docentes para la enseñanza de sus materias se pudo ver que a veces si se utilizan libros, paginas blogs, u otros recursos de los cuales los estudiantes puedan sacar información, esto nos hace notar que la información que forma parte de la bibliografía de los Lo que si satisface a los estudiantes es saber que el docente 
frecuentemente facilita dicha información a los estudiantes.

En el tema de asistencia, la mayoría de docentes no solo asiste a veces a clases regularmente, sino que también cumple con el horario de clases establecido. Es bueno saber también que los docentes están en su mayoría formando valores éticos-morales en los estudiantes, y no está demás afirmar que frecuentemente lo demuestran no solo con los alumnos sino también con sus colegas de trabajo en algunos casos.

\section{REFERENCIAS}

Álvares, C. (2017). Evaluación Docente en la Educación Superior: Un estudio de Caso Corporación Universitaria UNITEC. Universidad Militar Nueva Granada, (6), 67-72

Arbesú, M., \& García, J. (2017). La Evaluación Docente en Jaque: La Visión de los Funcionarios Universitarios. Revista Iberoamericana de Evaluación Educativa, 10(2), 171-185.

Ayalas, S. 2004. Proceso de Evaluación del Recurso Humano [en línea.

Carrillo, M., Zuñiga, B., \& Toscano, B. (2015). Percepción de los Estudiantes sobre la Evaluación al Desempeño Docente como un Instrumento para la Mejora de la Calidad Educativa. Caso: Facultad de Contaduría y Administración, Universidad Autónoma de Chihuahua.

Castellanos, D. et al. (2002). Aprender y enseñar en la escuela. La Habana: Editorial Pueblo y Educación.

Cadez, S., Dimovski, V., \& Zaman, M. (2017). Research, teaching and performance evaluation in academia: the salience of quality. Studies in Higher Education, 42(8), 1455-1473

Chacón, S. 2001. Evaluación de la calidad universitaria: validez de contenido. Psicothema [en línea]. 13 (2). Facultad de Psicología de la Universidad de Oviedo y el Colegio Oficial de Psicólogos del Principado de Asturias. Disponible en: http://www.psicothema.com/pdf/451.pdf [Consulta: 21 septiembre 2014]. Chiavenato, I. 1986. Introducción a la Teoría General de la Administración. México: Mc. Graw Hill.

Escudero Muñoz, J. M. (2006). El espacio europeo de educación superior. ¿Será la hora de la renovación pedagógica de la universidad? Murcia: ICE, Universidad de Murcia.

Elizalde, L. y Reyes, R. 2008. Elementos clave para la evaluación del desempeño de los docentes. Revista Electrónica de Investigación Educativa [en línea]. Especial. 
Disponible en: http://redie.uabc.mx/NumEsp1/contenido-elizaldereyes.html [Consulta: 21 septiembre 2014].

Fonseca, L. V. 2018. Diseño del proceso de Capital Humano para el Sistema de Gestión de la Calidad de la UNAH. Tesis de grado, Mayabeque.

Gehlbach, H., Robinson, C., Finefter, I., Benshoof, C., \& Schneider, J. (2018). Questionnaires as interventions.

González, S., Hidalgo, N. y Lombillo, I., 2017. La gestión del proceso de evaluación del desempeño de los docentes en la Educación Superior.

Hornstein, H. (2017). Student evaluations of teaching are an inadequate assessment tool for evaluating faculty performance. Cogent Education.

Kursanov, G. (2000). Problemas fundamentales del materialismo dialéctico. Ciencias Sociales. [ Links.

Lau, C. y Díaz, M. 2009. El sistema de gestión de los recursos humanos en las universidades [en línea]. (-). Disponible en: http://www.gestiopolis.com [Consulta: 21 septiembre 2014].

Luviano, J. 2008. Marco conceptual y metodológico para evaluar el desempeño docente en las maestrías del CENIDET [en línea]. (-). Disponible en: Http://www.cenidet.edu.mx/subaca/web-dda/docs/evaluacion2002.pdf [Consulta: 21 septiembre 2014].

Llerena, R. 1991. Evaluación del personal académico. Revista Perfiles Educativos, (53-54), 18-29.

López, M. 1999. A la calidad por la evaluación. Colección Gestión de la Calidad. España: Escuela Española.

Marczely, B. 1992. Teacher evaluation: research versus practice. Journal of Personnel Evaluation in Education, 5 (3), 270-272.

Moreno, T. (2016). Evaluación de la docencia en el ámbito universitario: la voz de los alumnos. Reencuentro,71,107-122.

Moreno, T. (2018). La Evaluación Docente en la Universidad: Visiones de los Alumnos. Revista Iberoamericana Sobre Calidad, Eficacia y Cambio En Educación, 16(3), 87101.

Moreno, L. (2018). Percepciones sobre el Sistema de Evaluación Docente de la Universidad Nacional Abierta y a Distancia UNAD (Universidad Externado de Colombia).

Ontoria, A. et al. (2006). Aprender con mapas mentales: una estrategia para pensar y estudiar. Madrid: Narcea. 
Pardo, J. (2017). Percepciones sobre la evaluación docente de estudiantes de la facultad de ciencias y educación de la Universidad Distrital Francisco José de Caldas.

Pérez, R. 1995. Evaluación de programas educativos. En: Rivilla, A. y Villar, Evaluación de programas educativos, centros y profesores. Madrid.

Pérez, A., Calderín, N., \& Fuentes, L. (2015). Percepciones de diferentes actores educativos sobre la evaluación docente en la Facultad de Educación de CECAR. Escenarios, 17 , $71-84$.

Reyes, E., González, E., \& Be, P. (2018). Evaluar la práctica docente a partir de los comentarios de estudiantes universitarios. Revista Iberoamericana de Educación, 76(2), 117-134.

Rizo, H. 1999. Evaluación del docente universitario: una visión institucional. Revista Iberoamericana de Educación 1.

Rodríguez, G. 2011.Evaluación orientada al aprendizaje estratégico en educación superior. Madrid: Narcea.

Sloep, berlanga, (2011). redes de aprendizaje, aprendizaje en red comunicar.

Unesco. (2008). Estándares de competencia en TIC para docentes. 